\title{
Towards a diagnostic adaptation science
}

\author{
Jochen Hinkel $^{1,2} \cdot$ Alexander Bisaro $^{1} \cdot$ Rob Swart $^{3}$
}

Received: 23 July 2015/ Accepted: 24 July 2015/Published online: 10 September 2015

(C) Springer-Verlag Berlin Heidelberg 2015

\section{Models of adaptation research}

How should climate change adaptation research be performed? Two principles are widely accepted and articulated in current adaptation-related research programmes such as the global Future Earth programme, the European Horizon 2020 programme and the Dutch Knowledge for Climate programme, just to name a few examples. The first one is that adaptation research should be transdisciplinary and solution-oriented (also called problem-oriented) in that it aims at contributing to "real-world" problem solving rather than purely advancing research in its own right (Cash et al. 2003; Gibbons et al. 1994; Moss et al. 2013). Achieving this aim entails co-designing and co-producing research together with stakeholders (Swart et al. 2014). The second principle is that adaptation research should be interdisciplinary in that it integrates knowledge from a range of natural and social science disciplines. And indeed, a wide variety of methods are currently applied in adaptation research, including participatory, experimental, decision analysis, behavioural analysis, institutional analysis and climate and impact simulation methods (Hinkel and Bisaro 2014).

Jochen Hinkel

hinkel@globalclimateforum.org

1 Adaptation and Social Learning, Global Climate Forum (GCF), Neue Promenade 6, 10178 Berlin, Germany

2 Division of Resource Economics, Albrecht Daniel Thaer Institute, Faculty of Life Sciences, Humboldt University, Unter den Linden 6, 10099 Berlin, Germany

3 Alterra Wageningen UR, Postbus 47, 6700 AA Wageningen, The Netherlands
Less consensus can be found on how exactly those two principles shall be put into practice. Regarding transdisciplinarity, there is a substantial literature that has proposed various definitions and models for transdisciplinary research, including "mode-2" knowledge production (Gibbons et al. 1994), post-normal science (Funtowicz and Ravetz 1993) and action research (Lewin 1946).

Regarding interdisciplinarity, there is hardly any dedicated literature exploring how to realise the integration of knowledge from diverse disciplines and beyond (Hinkel 2008). Nevertheless, there is a widespread model on how to combine methods, often called top-down approach (Dessai and Hulme 2004), which has dominated adaptation research from its beginnings. Climate models are run to produce climate scenarios, which are then downscaled and results are put into various sectoral climate impact models, sometimes followed by valuation methods to value projected climate impacts. Finally, the results may be fed into macroeconomic models in order to estimate economy-wide implication and/or decision analysis methods.

But is the top-down model the only meaningful model of interdisciplinarity for climate adaptation? It certainly was a meaningful model in the early days of climate change research when the main question addressed was by how much adaptation could offset climate impacts at an aggregate level in order to prevent "dangerous anthropogenic interference with the climate system", which is the ultimate objective of the United Nations Framework Convention on Climate Change (UNFCCC 1992, Article 2). In recent years, adaptation has become a practical necessity, and the field has progressed from focusing on questions concerning climate impacts and costs and benefits of adaptation at an international scale to a much wider array of questions at all scales, related to, e.g., human perception, institutional change, equity, development and barriers to 
adaptation (Meinke et al. 2009; Moss et al. 2013). Consequently, the array of methods applied has expanded considerably and particularly into the domain of social sciences.

Today, it is probably fair to say that there is no canonical model for integrating disciplines in climate change adaptation research. While there are still strong proponents of the top-down model, there are also other strong voices arguing for different, or additional, models of interdisciplinarity to address the evolving nature of questions related to the development, implementation and evaluation of adaptation options. An example of the former is the European Commission's EU Adaptation Strategy that states that the main knowledge gaps relate to information on damage and adaptation costs and benefits; regional- and local-level analyses and risk assessments; tools to support decision making; and to assess how effective the various adaptation measures are (European Commission 2013). Examples of the latter include those who argue that climate information and adaptation cost/benefits are not a limit to adaptation (Dessai et al. 2008; Eakin and Patt 2011), and those who argue that research might not be needed at all or only to a small extent, as adaptation is primarily a matter of practice and social learning (van Aalst et al. 2008).

\section{A diagnostic form of transdisciplinarity}

This special issue suggests a novel model of interdisciplinarity, which we call a diagnostic model. This model encompasses the aforementioned diversity of methods (including impact and decision analysis), but compliments this with a meta-level analysis of which combination of methods is most salient to apply from the solution-oriented perspective. From a research perspective, all methods might be applicable, but from a solution-oriented perspective, one may prefer certain methods that, given time and resource constraints, are most salient to advancing adaptation on the ground. For example, reducing uncertainties in impact projections may be less salient in a situation where adaptation is constrained by institutional barriers. Instead, institutional analysis that may help to remove barriers may be more salient in this situation.

Importantly, we do not intend to exclude any method a priori nor do we believe that only one method is applicable in a given situation. For any particular adaptation situation, more than one method may be suitable, providing different, complementary insights. Still, not all methods are equally salient in all situations and our aim is to foster an interdisciplinary debate about this. Consequently, we see "adaptation science" not as a new discipline but rather as a meta-science trying to understand which disciplinary, interdisciplinary or transdisciplinary expertise to apply in a given situation. We argue that this meta-level perspective is as essential to solution-driven research as is the inclusion of stakeholders. While the latter is emphasised throughout the literature, the former has hardly received any attention in the field of climate adaptation until now.

Medical science offers a useful analogy for what we envisage here. Similar to adaptation, this science is characterised through a diversity and complexity of problems (i.e. diseases). It also applies a diversity of methods to diagnose and treat diseases, and also has to grapple with uncertainties, some of which are irreducible. Despite this, the field has managed to build up a coherent approach to diagnosing and treating diseases that flexibly draws upon a wide range of diverse specialist expertise. This diagnostic approach involves sequentially narrowing down the problem at hand through a series of diagnostic questions and methods applied, whereby the next step addressed depends on the results of the preceding ones. Diagnosis proceeds along these lines until a sufficiently clear clinical pattern has been established and medical treatment can start. This is similar to what we envisage for solution-oriented research. Steps of research are conducted iteratively until a sufficiently clear understanding of the adaptation problem emerges and practice can start.

The main challenge in realising this diagnostic model in adaptation research is a lack of recognition of, and terminology for, the great diversity of problems addressed under the broad concept of adaptation. Adaptation is studied at all scales and across sectors, regions, policy domains and groups of people and encompasses such diverse problems as climate-proofing capital investment, promoting collective action amongst resource users, main-streaming climate resilience considerations into policy domains, planning large-scale flood protection infrastructure and empowering communities to mobilise their own resources to adjust to increasing frequency of extreme weather events.

Despite this diversity of adaptation problems, a lot of literature, including large parts of the reports of the Intergovernmental Panel on Climate Change (IPCC), reads as if adaptation was one single, narrowly defined type of problem. While the attention paid to adaptation grew considerably in the IPCC assessment reports (e.g. from one dedicated chapter in the Fourth Assessment Report to four chapters in the Fifth Assessment Report), it is still mostly addressed generically, with at most sectoral and regional differences. Consequently, terminological development has focused on finding categories, such as planned versus reactive adaptation (Füssel 2007) or incremental versus transformative adaptation (Kates et al. 2012; O'Brien 2012), that equally apply to all adaptation situations. While there are certainly merits in these efforts, the downside is that general categories impede the differentiated methodological debate necessary for bringing in the most relevant 
expertise for solving a given adaptation problem. Again similarly to medical sciences, a huge body of knowledge and specialised terminology has accumulated in many adaptation-relevant fields and disciplines. Solution-oriented research should strive to use this rich knowledge base.

First steps towards such a diagnostic model of interdisciplinarity have already been taken by the literature that distinguishes different types of barriers preventing adaptation (Moser et al. 2012; Moser and Ekstrom 2010). This includes barriers that may arise from a lack of climate information (Dessai et al. 2008), individual risk and capacity perception (Grothmann and Patt 2005), legislative and regulatory frameworks (Gupta et al. 2010), or conflicting values (Adger et al. 2009; Benzie 2014; Hughes 2013). Diagnosing the type of barrier present in a given situation provides an entry point for bringing in specific expertise required. To date, however, little attention has been paid to understanding how and why barriers emerge (Biesbroek et al. 2013; Eisenack et al. 2014), which is exactly the point of departure of the diagnostic perspective elaborated here.

\section{The MEDIATION project and this special issue}

This special issue reports on the results of the Europeanfunded MEDIATION project that developed and applyed a diagnostic approach to a diverse set of case studies in Europe. The aim was to systematically clarify in which adaptation situation which methods may be used to provide results that can support adaptation practice. Towards this end, MEDIATION has developed (1) a more precise and specific language for describing the various challenges addressed and methods applied under the broad labels of adaptation; and (2) a diagnostic adaptation framework $(D A F)$ that matches adaptation challenges to appropriate methods for addressing them.

Following the diagnostic model of adaptation research outlined above, the MEDIATION research design included two nested streams of research. The first stream consisted of a set of stakeholder-driven adaptation case studies addressing a range of adaptation issues at regional, national and sub-national levels. Each case addressed sequences of questions that were identified iteratively together with stakeholders. That is, a first question was formulated, methods were selected, and results generated, and then, based on these results, a new question was formulated.

At a regional level, Khabarov et al. (2014) assess forest fire risk and adaptation options in three regions of Europe by developing a stand-alone fire model (SFM) for projecting climate change impacts and adaptation options. Slobbe et al. (2014) analyse future impacts of low-flow events in the Rhine river basin and identify climate risks and adaptation options with respect to salmon restoration policy and shipping. For Scandinavia, Carter et al. (2014) identify climate-related health risks for elderly people in three Nordic countries by developing a vulnerability index composed of exposure and adaptive capacity indicators.

Another five cases were carried out at national and subnational levels. Tainio et al. (2014) analyse climate change impacts on butterfly habitat in Finland and apply a robust decision-making method to choose between options for conserving key butterfly species. Varela-Ortega et al. (2014) analyse adaptation to climate change impacts on water use and crop yields in the Spanish Guadiana river basin, based on stakeholder preferences on different water management options, including increasing storage capacity, changing crop varieties and developing an insurance system. Zhu et al. (2014) analyse climate change impacts on wine production in Tuscany and the impact of different adaptation options using an economic optimisation model. Holman et al. (2014) analyse cross-sectoral impacts and robust adaptation policy options, together with Scottish stakeholders, using the CLIMSAVE (Climate Change Integrated Assessment Methodology for Cross-Sectoral Adaptation and Vulnerability in Europe; Harrison et al. 2015) platform, developed in a project implemented under the same call as MEDIATION.

The second stream of research was meta-level research about the research conducted in the case studies of the first stream of research described above. On this meta-level, data were recorded on the adaptation challenges addressed, the approach applied and the results achieved as well as empirical, theoretical and normative criteria applied for selecting the questions and methods. Data were gathered through a set of structured questionnaires completed by each case study leader. This was supplemented with a review of the adaptation literature and in-depth discussion with case study researchers as well as amongst the whole project team at biannual meetings. From these data, the diagnostic adaptation framework (DAF) was developed as described in Hinkel and Bisaro (2014).

Generally, this framework has helped researchers in the MEDIATION project to better understand, communicate and discuss the challenges addressed, methods applied and results achieved in a range of adaptation case studies. The framework also constitutes the basis of the recently published guidance on methods for vulnerability, impacts and adaptation by the Global Programme of Research on Climate Change Vulnerability, Impacts and Adaptation (PROVIA 2013).

The two final papers of this special issue evaluate and synthesise the overall results achieved. Werners et al. (2014) test the resulting diagnostic framework by comparing the research methods it suggests with methods 
actually applied in the Dutch Delta Programme. Finally, Bisaro et al. (2015) synthesises findings across all case studies in terms of the strengths and weaknesses of individual methods applied, as well as patterns of sequences of methods observed.

\section{References}

Adger WN, Dessai S, Goulden M, Hulme M, Lorenzoni I, Nelson DR, Næss LO, Wolf J, Wreford A (2009) Are there social limits to adaptation to climate change? Clim Change 93:335-354. doi:10. 1007/s10584-008-9520-z

Benzie M (2014) Social justice and adaptation in the UK. Ecol Soc 19. doi:10.5751/ES-06252-190139

Biesbroek GR, Klostermann JEM, Termeer C, Kabat P (2013) On the nature of barriers to climate change adaptation. Reg Environ Change 13:1119-1129. doi:10.1007/s10113-013-0421-y

Bisaro A, Swart R, Hinkel J (2015) Frontiers of solution-oriented adaptation research. Reg Environ Change. doi:10.1007/s10113015-0766-5

Carter TR, Fronzek S, Inkinen A, Lahtinen I, Lahtinen M, Mela H, O'Brien KL, Rosentrater LD, Ruuhela R, Simonsson L, Terama E (2014) Characterising vulnerability of the elderly to climate change in the Nordic region. Reg Environ Change. doi:10.1007/ s10113-014-0688-7

Cash DW, Clark WC, Alcock F, Dickson NM, Eckley N, Guston DH, Jäger J, Mitchell RB (2003) Knowledge systems for sustainable development. Proc Natl Acad Sci 100:8086-8091. doi:10.1073/ pnas. 1231332100

Dessai S, Hulme M (2004) Does climate adaptation policy need probabilities? Clim Policy 4:107-128. doi:10.3763/cpol.2004. 0411

Dessai S, Hulme M, Lempert R, Pielke R Jr (2008) Climate prediction: a limit to adaptation? In: Adger WN, Lorenzoni I, O'Brien KL (eds) Adapting to climate change: thresholds, values, governance. Cambridge University Press, Cambridge, pp 64-78

Eakin HC, Patt A (2011) Are adaptation studies effective, and what can enhance their practical impact? WIREs Clim Change 2:141-153. doi:10.1002/wcc.100

Eisenack K, Moser SC, Hoffmann E, Klein RJT, Oberlack C, Pechan A, Rotter M, Termeer CJAM (2014) Explaining and overcoming barriers to climate change adaptation. Nature Clim Change 4:867-872. doi:10.1038/nclimate2350

European Commission (2013) An EU strategy on adaptation to climate change, communication from the commission to the European Parliament, the Council, the European and Social Committee and the Committee of the Regions, Brussels

Funtowicz SO, Ravetz JR (1993) Science for the post-normal age. Futures 25:739-755

Füssel M (2007) Adaptation planning for climate change: concepts, assessment approaches, and key lessons. Sustain Sci 2:265-275. doi:10.1007/s11625-007-0032-y

Gibbons M, Limoges C, Nowotny H, Schwartzman S (1994) The new production of knowledge. The dynamics of science and research in contemporary societies. Sage, London

Grothmann T, Patt A (2005) Adaptive capacity and human cognition: the process of individual adaptation to climate change. Global Environ Change Part A 15:199-213. doi:10.1016/j.gloenvcha. 2005.01.002

Gupta J, Termeer C, Klostermann J, Meijerink S, van den Brink M, Jong P, Nooteboom S, Bergsma E (2010) The adaptive capacity wheel: a method to assess the inherent characteristics of institutions to enable the adaptive capacity of society. Environ Sci Policy 13:459-471. doi:10.1016/j.envsci.2010.05.006

Harrison PA, Holman IP, Berry PM (2015) Assessing cross-sectoral climate change impacts, vulnerability and adaptation: an introduction to the CLIMSAVE project. Clim Change 128:153-167. doi:10.1007/s10584-015-1324-3

Hinkel J (2008) Transdisciplinary knowledge integration. Cases from integrated assessment and vulnerability assessment. Environmental Systems Analysis Group, Wageningen University, Wageningen

Hinkel J, Bisaro A (2014) Methodological choices in solutionoriented adaptation research: a diagnostic framework. Reg Environ Change. doi:10.1007/s10113-014-0682-0

Hinkel J, Bisaro A (2014) A review and classification of methods for climate change adaptation. WIREs Clim Change. doi:10.1002/ wcc. 322

Holman IP, Harrison PA, Metzger MJ (2014) Cross-sectoral impacts of climate and socio-economic change in Scotland: implications for adaptation policy. Reg Environ Change. doi:10.1007/s10113014-0679-8

Hughes S (2013) Justice in urban climate change adaptation: criteria and application to Delhi. Ecol Soc 18. doi:10.5751/ES-05929180448

Kates RW, Travis WR, Wilbanks TJ (2012) Transformational adaptation when incremental adaptations to climate change are insufficient. PNAS 109:7156-7161. doi:10.1073/pnas.1115521109

Khabarov N, Krasovskii A, Obersteiner M, Swart R, Dosio A, SanMiguel-Ayanz J, Durrant T, Camia A, Migliavacca M (2014) Forest fires and adaptation options in Europe. Reg Environ Change. doi:10.1007/s10113-014-0621-0

Lewin K (1946) Action research and minority problems. J Soc Issues 2:34-46. doi:10.1111/j.1540-4560.1946.tb02295.x

Meinke H, Howden SM, Struik PC, Nelson R, Rodriguez D, Chapman SC (2009) Adaptation science for agriculture and natural resource management - urgency and theoretical basis. Curr Opin Environ Sustain 1:69-76. doi:10.1016/j.cosust.2009.07.007

Moser SC, Ekstrom JA (2010) A framework to diagnose barriers to climate change adaptation. Proc Natl Acad Sci 107:2202622031. doi:10.1073/pnas.1007887107

Moser SC, Williams J, Boesch DF (2012) Wicked challenges at land's end: managing coastal vulnerability under climate change. Ann Rev Environ Resourc 37:51-78. doi:10.1146/annurev-environ021611-135158

Moss RH, Meehl GA, Lemos MC, Smith JB, Arnold JR, Arnott JC, Behar D, Brasseur GP, Broomell SB, Busalacchi AJ, Dessai S, Ebi KL, Edmonds JA, Furlow J, Goddard L, Hartmann HC, Hurrell JW, Katzenberger JW, Liverman DM, Mote PW, Moser SC, Kumar A, Pulwarty RS, Seyller EA, Turner BL, Washington WM, Wilbanks TJ (2013) Hell and high water: practice-relevant adaptation science. Science 342:696-698. doi:10.1126/science. 1239569

O'Brien K (2012) Global environmental change II from adaptation to deliberate transformation. Prog Hum Geogr 36:667-676. doi:10. $1177 / 0309132511425767$

PROVIA (ed) (2013) PROVIA guidance on assessing climate change vulnerability, impacts and adaptation. United Nations Environment Programme, Nairobi

Slobbe EV, Werners SE, Riquelme-Solar M, Bolscher T, van Vliet MTH (2014) The future of the Rhine: stranded ships and no more salmon? Reg Environ Change. doi:10.1007/s10113-0140683-z

Swart R, Biesbroek R, Capela Lourenço T (2014) Science of adaptation to climate change and science for adaptation. Front Environ Sci Interdiscip Clim Stud 2 (29). doi:10.3389/fenvs. 2014.00029 
Tainio A, Heikkinen RK, Heliölä J, Leikola N, Lötjönen S, Mashkina O, Carter TR, Bharwani S, Hunt A, Taylor R, Watkiss P (2014) Conservation of grassland butterflies in Finland under a changing climate. Reg Environ Change. doi:10.1007/s10113-014-0684-y

UNFCCC (1992) The United Nations Framework Convention on Climate Change. Available at: http://unfccc.int/key_documents/ the_convention/items/2853.php

Van Aalst MK, Cannon T, Burton I (2008) Community level adaptation to climate change: the potential role of participatory community risk assessment. Global Environ Change 18:165-179. doi:10.1016/j.gloenvcha.2007.06.002

Varela-Ortega C, Blanco I, Esteve P, Bharwani S, Fronzek S, Downing TE (2014) How can irrigated agriculture adapt to climate change? Insights from the Guadiana basin in Spain. Reg Environ Change. doi:10.1007/s10113-014-0720-y

Werners SE, van Loon-Steensma JM, Oost AP (2014) Method selection in adaptation research: the case of the Delta Programme for the Dutch Wadden region. Reg Environ Change. doi:10.1007/s10113-015-0799-9

Zhu X, Moriondo M, van Ierland EC, Trombi G, Bindi M (2014) A model-based assessment of adaptation options for Chianti wine production in Tuscany (Italy) under climate change. Reg Environ Change. doi:10.1007/s10113-014-0622-z 